\title{
Book Review: Philosophy of STEM Education - A Critical Investigation
}

\author{
Olivia Nichole Ritter \\ University of Tennessee, United States
}

As a high school Biology and Chemistry teacher and Science Education doctoral student, I know that the current emphasis on STEM education is a prevalent force in education. STEM buzzwords and concepts infiltrate practically every classroom in one way or another, to the point it seems the STEM education movement is ubiquitous. Recognizing STEM as an acronym for science, technology, engineering, and math seems simple enough; yet there are varying visions of the how, what, and why of STEM education - what is actually taking place and the reasons behind the movement. The confusion surrounding the true meaning and purposes of STEM education, even on the part of teachers in STEM-related fields, warrants elucidation and deeper investigation. Philosophy of STEM Education: A Critical Investigation (ISBN 978-1-137-53545-0) was published in 2015 by Palgrave Macmillan in the United States as a part of the Palgrave Pivot series on the Cultural and Social Foundations of Education. The book has a total of 105 pages.

In this book, Nataly Chesky and Mark Wolfmeyer seek to navigate the specific aims of STEM initiatives, the assumptions that undergird these aims, and the potential consequences of these STEM initiatives. While this book does not offer specific strategies for moving in the revolutionary directions proposed by the authors, the philosophical approach and findings of Chesky and Wolfmeyer's investigation provide a foundation for educators, administrators, and policymakers to begin contemplating alternatives to current STEM education policy objectives.

To begin, the authors discuss the history and evolution of STEM education, as well as provide a brief review of STEM policy critiques. Chesky and Wolfmeyer state, "STEM education policy is historically entrenched with nationalistic goals of militarism and economic security" (p. 6). They suggest that the objectives of STEM education include developing well-informed democratic citizens and highly competent workers, in addition to integrating the fields of science, technology, engineering, and math.

Delving deeper into the underpinnings of STEM education policies, Chesky and Wolfmeyer employ a philosophical approach to examining STEM education policy documents in order "to understand the complex web that interconnects its inherent subject matter, pedagogy, and purpose" (p. 16). These researchers justify their use of a philosophical lens by stating that it:

opens up a space for potentially new visions of how philosophy of STEM education can play a role in discourses and how educators can enact real change in their own classrooms while navigating the education policy landscape that governs how and why they teach STEM. ( $p$. 11) 
STEM is emphasized as a socially constructed discourse that responds to the circumstances of society and the efforts of the world's powerful and elite. The authors' views reflect critiques of math and science education policies, which claim that these policies are biocapitalist in nature and serve neoliberal economic objectives. The critiques assert that these antidemocratic STEM education policies further social inequities in the U.S. and reduce students to natural resources whose main purpose is to bring in a profit for those in charge.

Chesky and Wolfmeyer identify and discuss the epistemologies, ontologies, and axiologies that permeate the fields of science, mathematics, and the STEM movement. The authors draw parallels between the dominant constructivist epistemologies influencing pedagogies in science and mathematics education. Effects of traditional and transformative approaches on math and science pedagogy are also investigated. Chesky and Wolfmeyer refer to the transformative ethnomathematics and critical mathematics pedagogies, as well as the socio-scientific issues and science-technology-society movements in science education, noting the moral, historical, political, societal, and cultural aspects of each.

The axiologies, which include the underlying motives, ethical issues, and values of STEM education, are further scrutinized. Consumerism and human capital development are identified as the mainstream goals of STEM education, with alternative views of "potentialities for a value set more sympathetic to critical, social reconstructionist schooling," including "aesthetic appreciation and social and environmental justice" (p. 37). Chesky and Wolfmeyer argue that "STEM is deeply entrenched with societal values and concerns," and their interest lies in "understand[ing] the link between society and STEM" (p. 38). Specifically, the aims (axiologies) of mathematics education are categorized as utilitarian, cognitive, and democratic. Examples are given to characterize each of these aims, but the authors also make the case that the boundaries between these aims are sometimes blurred and interconnectedness can exist. The investigated epistemologies include traditional, constructivist, and transformative, while the ontological conceptions of STEM education include absolutism, fallibilism, and aesthetics.

The researchers employed both quantitative and qualitative methodologies in their critical inquiry into STEM education policy. The policy document search and content analysis procedures are articulated, using a framework centered around set theory. These axiology-, ontology-, and epistemology-based coding constructs were used in the analysis of 38 publically accessible STEM education policy documents. The descriptive findings are, at first, straightforward enough, with tables and graphs presenting the number of occurrence of each of the constructs. Axiological codes were the most prevalent, an expected outcome since policies are typically centered around objectives of initiatives, with utilitarian axiology having the highest number of coding instances. The overall most common code found in all 38 documents, however, was traditional epistemology. Ontologies as a whole were the least common code encountered, with absolutist having the highest number of occurrences, 87 , and fallibilistic having the lowest at only seven. Chesky and Wolfmeyer found it notable that the aesthetic ontology, 57, had almost as many occurrences as absolutist, 87.

The authors' sought to discover areas in the policy discourse where revolutionary change can be made. They suggest these areas exist within a "Badiouian 'void,'" when something is "presented but not represented, belong[s] but not included" (p. 62-63). This prompts the use of set theory functions in an extensive analysis of the 38 documents, using "unions," "intersections," and lengthy strings of 
letters and symbols showing the inclusion and exclusion of the nine coding constructs within each document. According to this method of analysis, the void was found to lie in the transformative epistemology; Chesky and Wolfmeyer explain, "this is the element least represented in the policy documents, yet on the rare occasions that it is, all other elements in all the policy documents are also represented" (p. 74).

This "void" in STEM education is further explored in the context of critical theory. Special attention is paid to the influences of mathematics on essentially all aspects of our lives. These researchers aver that, "critical educators can seize upon STEM as a space for contestations and constructions situated within social contexts," calling for transformative STEM education that results in the production of scientific knowledge within the settings of social life (p. 79-80).

The authors also highlight the aesthetic potential of STEM education, with an emphasis on mathematics. Chesky and Wolfmeyer make the claim that "mathematics and science need not be 'useful' in all cases," and that aesthetics deserve to be "appreciated on their own terms and for nothing" (p. 89). Additionally, they believe the connectedness between science and mathematics warrants attention. By viewing STEM education through these critical lenses, Chesky and Wolfmeyer:

reimagine the axiological objectives of STEM education to be centered around not only imagining sustainable technology, but also about harnessing aesthetic awareness, drawing on environmental-sensibilities, awakening cultural, gender, and class critical consciousness, and about nothing at all. (p. 89)

These words exemplify the authors' call to action. They expose a myth of progress, where "associating science with technology, adding a dash of rational, objective, value-free mathematics, comes together as the perfect storm for progress" (p. 82); they envision a new and improved STEM education - one that exists to expose the beauty in learning mathematics and science, and consequently STEM; and they seek to improve the quality of life for students rather than simply pump out a profitable workforce in the name of biocapitalism.

Ironically, one criticism of this book lies in the lack of transparency regarding the mathematical methods used in the authors' analyses. Some of the calculations and procedures utilized in this study require further clarification. For example, the computation and significance of the means on page 56 are ambiguous; each mean is simply the maximum value divided by 4 , and how the authors arrived at the decision to divide by 4 instead of 38 , the number of documents, is unclear. Other minor errors, such as referring to tables as bar graphs, are small annoyances that detract from the book's thesis.

Despite the slight irregularities outlined in the paragraph above, this book's value lies in the succinct provision of evidence that confounds simplistic views of the objectives and potential directions of STEM education. More importantly, this book elicits significant questions about how the proposed alternative conceptions of STEM may materialize. As an educator in a system dominated by highstakes standardized testing, the authors' perspectives concerning the importance of the intrinsic value of genuine learning and the aesthetics underlying the subjects of mathematics and science are refreshing and provide hope for potential change. Both of these ideals currently seem to be 
placed on the back burner, and the likeliness of this potential transformation of STEM education remains uncertain at best. Other than a brief statement about the education of future math and science teachers on page 94 , the book does not explicitly address which actions need to be taken to move toward this revolutionary change or who should take the initiative to evoke this change. Amidst the politics and accountability choices made by the powerfully elite, I am left wondering what influence educators can have to stimulate and drive STEM education in this direction. Increasing awareness of the actual motives underlying STEM education policy and presenting the possibility of redirecting and restructuring these motives seem to be steps in direction of shifting policies toward providing more comprehensive and beneficial STEM education. Teachers, administrators, and policymakers could benefit from reading Philosophy of STEM Education: A Critical Investigation because of its in-depth philosophical perspectives regarding STEM education and the light it sheds on current and future STEM education policies.

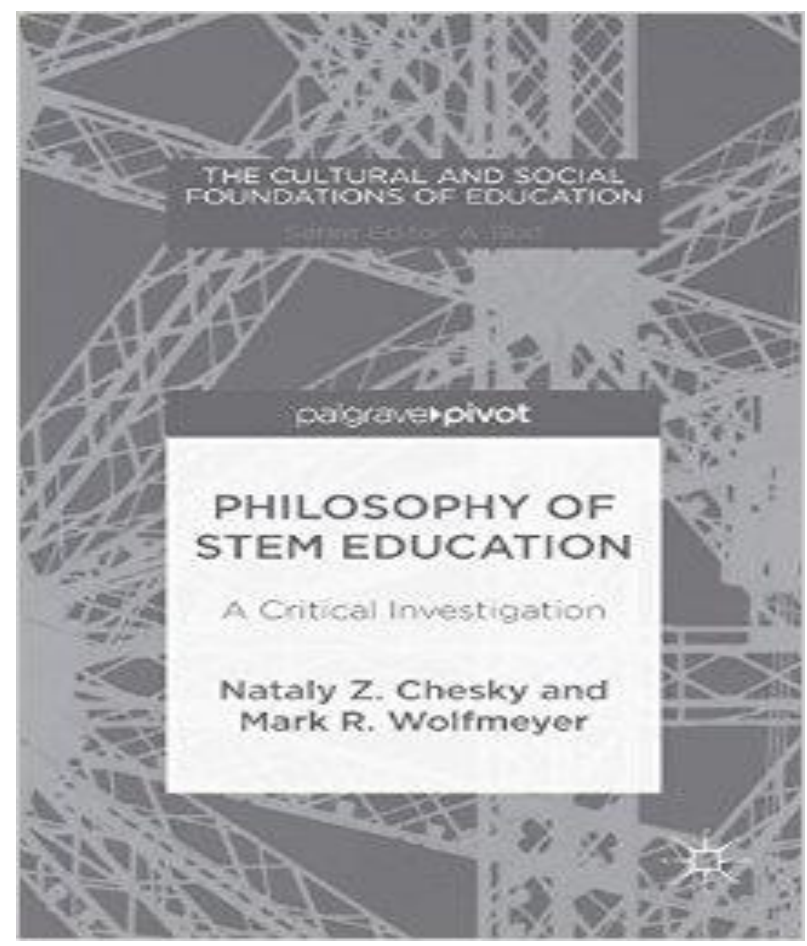

Correspondence: Olivia Nichole Ritter, Doctoral Student in Science Education, Department of Theory and Practice in Teacher Education, University of Tennessee, Knoxville, Tennessee, United States. 